\title{
Space and ground segment performance and lessons learned of the FORMOSAT-3/COSMIC mission: four years in orbit
}

\author{
C.-J. Fong ${ }^{1}$, D. Whiteley ${ }^{2}$, E. Yang ${ }^{1}$, K. Cook $^{4}$, V. Chu ${ }^{1}$, B. Schreiner ${ }^{5}$, D. Ector ${ }^{2}$, P. Wilczynski ${ }^{2}$, T.-Y. Liu ${ }^{1}$, and \\ N. Yen ${ }^{1}$ \\ ${ }^{1}$ National Space Organization (NSPO), HsinChu, Taiwan \\ ${ }^{2}$ National Oceanic and Atmospheric Administration (NOAA), Silver Spring, MD, USA \\ ${ }^{3} \mathrm{C}^{2}$ International, LLC, Kimball, SD, USA \\ ${ }^{4}$ University Corporation for Atmospheric Research (UCAR), Boulder, CO, USA
}

Received: 4 December 2010 - Published in Atmos. Meas. Tech. Discuss.: 24 January 2011

Revised: 11 May 2011 - Accepted: 26 May 2011 - Published: 17 June 2011

\begin{abstract}
The FORMOSAT-3/COSMIC (Constellation Observing System for Meteorology, Ionosphere, and Climate) Mission consisting of six Low-Earth-Orbit (LEO) satellites is the world's first demonstration constellation using radio occultation signals from Global Positioning System (GPS) satellites. The atmospheric profiles derived by processing radio occultation signals are retrieved in near real-time for global weather/climate monitoring, numerical weather prediction, and space weather research. The mission has processed, on average, 1400 to 1800 high-quality atmospheric sounding profiles per day. The atmospheric radio occultation data are assimilated into operational numerical weather prediction models for global weather prediction, including typhoon/hurricane/cyclone forecasts. The radio occultation data has shown a positive impact on weather predictions at many national weather forecast centers. A follow-on mission was proposed that transitions the current experimental research mission into a significantly improved real-time operational mission, which will reliably provide 8000 radio occultation soundings per day. The follow-on mission, as planned, will consist of 12 LEO satellites (compared to 6 satellites for the current mission) with data latency requirement of $45 \mathrm{~min}$ (compared to $3 \mathrm{~h}$ for the current mission), which will provide greatly enhanced opportunities for operational forecasts and scientific research. This paper will address the FORMOSAT-3/COSMIC system and mission overview, the spacecraft and ground system performance after four years in orbit, the lessons learned from the encountered technical challenges and observations, and the expected design improvements for the spacecraft and ground system for FORMOSAT-7/COSMIC-2.
\end{abstract}

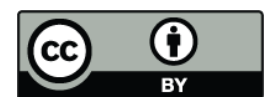

Correspondence to: $\mathrm{K}$. Cook (kcook@c2iconsulting.com)

\section{Introduction}

The FORMOSAT-3/COSMIC (Constellation Observing System for Meteorology, Ionosphere, and Climate) (FS-3/C) Mission is a joint Taiwan-US demonstration satellite mission that was launched in April 2006. The objective of FS$3 / \mathrm{C}$ is to demonstrate the value of near-real-time GPS Radio Occultation (GPS-RO) observations in operational numerical weather prediction. FS-3/C is currently providing global GPS-RO data in near-real-time to over 1400 users in more than 52 countries. The GPS-RO data has been demonstrated to be a valuable asset to the climate, meteorology, and space weather communities. The GPS/Meteorology (GPS/MET) experiment (1995-1997) showed that the GNSS-RO technique offers great advantages over the traditional passive microwave measurement of the atmosphere by satellites and became the first space-based "proof-of-concept" demonstration of GNSS-RO mission impacts (Ware et al., 1996; Kursinski et al., 1996; Rius et al., 1998; Anthes et al., 2000; Hajj et al., 2000; Kuo et al., 2000). For a more complete history of GNSS-RO see Yunck et al. (2000) and Melbourne (2005).

"The extraordinary success of the GPS/MET mission inspired a series of other RO missions, e.g., Ørsted (1999), SUNSAT (1999), Satélite de Aplicaciones Científicas-C (SAC-C) (2001), the Challenging Minisatellite Payload (CHAMP) (2001), and the twin Global GNSS Radio Occultation Mission for Meteorology, Ionosphere \& Climate Gravity Recovery and Climate Experiment (GRACE) (2002), Europe's meteorology operational satellite series (MetOp-A in 2006) (Luntama et al., 2008), and Oceansat-2 (2009) (Perona et al., 2007)."

The FS-3/C mission uses single differencing to extract excess atmospheric phases for each occultation event because it is less susceptible to GPS ground station tracking errors

Published by Copernicus Publications on behalf of the European Geosciences Union. 
(Schreiner et al., 2009). FS-3/C has proven to increase the accuracy of the predictions of hurricane/typhoon/cyclone behavior, significantly improve long-range weather forecasts, and monitor climate change with unprecedented accuracy (Anthes et al., 2000, 2008; Kuo et al., 2000, 2004, 2008; Liou et al., 2007). The success of the FS-3/C mission has initiated a new era for near real-time operational exploitation of global navigation satellite system (GNSS) RO soundings (Yunck et al., 2000).

However, the FS-3/C Mission will reach the end of its five-year design life in 2011, and the critical real-time satellite observing capability will begin to degrade as satellites become no longer operational. As a result, the National Space Organization (NSPO) and National Oceanic and Atmospheric Administration (NOAA) intend to jointly develop the FORMOSAT-7/COSMIC-2 (FS-7/C-2) Mission. FS$7 / \mathrm{C}-2$ will incorporate the next generation GNSS-RO receiver, a significantly improved spacecraft design, and more substantial ground communication network for data download (Chu et al., 2008; Fong et al., 2008c, 2009a, b).

FS-7/C-2 is intended to provide continuity of the GPSRO data as well as provide the next generation of GNSS-RO data to the scientific community and the global weather centers. The objective of the FS-7/C-2 Mission is to collect a large amount of atmospheric and ionospheric data primarily for operational weather forecasting and space weather monitoring as well as meteorological, climate, ionospheric, and geodetic research. In addition, the system will allow scientists to collect data over unpopulated and remote regions (such as the polar and oceanic regions) in support of research in these areas. This paper will address the FS-3/C system and mission overview, the spacecraft and ground system performance after four year in orbit, the lessons learned from the encountered technical challenges and observations, and the expected design improvements for the new FS-7/C-2 spacecraft and ground system.

\section{FS-3/C system and mission overview}

The FS-3/C space segment includes six Low-Earth-Orbit (LEO) satellites in a constellation-like formation. The FS3/C satellite constellation was successfully launched into the same orbital plane at $516 \mathrm{~km}$ altitude at 01:40 UTC on 15 April 2006. The FS-3/C satellites are equipped with three onboard payloads including a GPS Occultation Receiver (GOX), a Tri-Band Beacon (TBB), and a Tiny Ionospheric Photometer (TIP). The satellite constellation was intended to include six orbit planes at $800 \mathrm{~km}$ final mission altitude with 30 degree separation for evenly distributed global coverage.

The FS-3/C system that is in operation today consists of six satellites, a Satellite Operations Control Center (SOCC) in Taiwan, four remote tracking stations (RTSs), two local tracking stations (LTSs), two data processing centers, and a fiducial network. The SOCC uses the real-time telemetry and the back orbit telemetry to monitor, control, and manage the spacecraft state-of-health. There are two LTSs: one located in Chungli, Taiwan and the other in Tainan, Taiwan. There are four RTSs operated by NOAA to support the satellite passes: Fairbanks Command and Data Acquisition Station (FCDAS) in Fairbanks, Alaska and Kongsberg Satellite Services Ground Station (KSAT) in Troms $\varnothing$, Norway, which are currently the two primary stations for the mission. The Wallops station in Virginia and the McMurdo station in McMurdo, Antarctica provide backup support as needed for the mission (Fong et al., 2008c, 2009a, b).

The science RO data is downlinked from the satellites to the RTS and then transmitted from the RTS via NOAA to the two data processing centers. The two data processing centers are the CDAAC (COSMIC Data Analysis and Archive Center) located in Boulder, Colorado and the TACC (Taiwan Analysis Center for COSMIC) located at the Central Weather Bureau (CWB) in Taiwan. The fiducial GNSS data is combined with the occulted and referenced GNSS data from the GOX payload to remove the satellite clock errors.

The science data collected by the GOX and TIP payloads are processed by the CDAAC and TACC. The results processed by the CDAAC are then passed to the National Environmental Satellite, Data, and Information Service (NESDIS) at NOAA. These data are further routed to the international weather centers including the Joint Center for Satellite Data Assimilation (JSCDA), National Centers for Environment Prediction (NCEP), European Centre for Medium-Range Weather Forecasts (ECMWF), United Kingdom Meteorological Office (UKMO), Japan Meteorological Agency (JMA), Air Force Weather Agency (AFWA), Canadian Meteorological Centre (Canada Met), French National Meteorological Service (Météo France), and Taiwan's CWB. The data are provided to the global weather centers within $180 \mathrm{~min}$ to meet the data latency limit required to be assimilated into the numerical weather prediction (NWP) models.

\section{Spacecraft performance after four years in orbit}

\subsection{Spacecraft constellation performance}

The FS-3/C in-orbit system performance over the last four years is considered to be more than satisfactory in meeting its mission goals. The experimental constellation was defined to have a two-year spacecraft mission life, and a spacecraft design life of five-years. The spacecraft hardware failure and/or degradation are proceeding as anticipated. Although the expectation of the entire 6-satellite constellation continuing operations into the fifth year and beyond is not realistic, a partial constellation with degraded performance is likely to continue for a few more years. It is believed that the lessons learned from the in-orbit operations will provide a solid foundation 


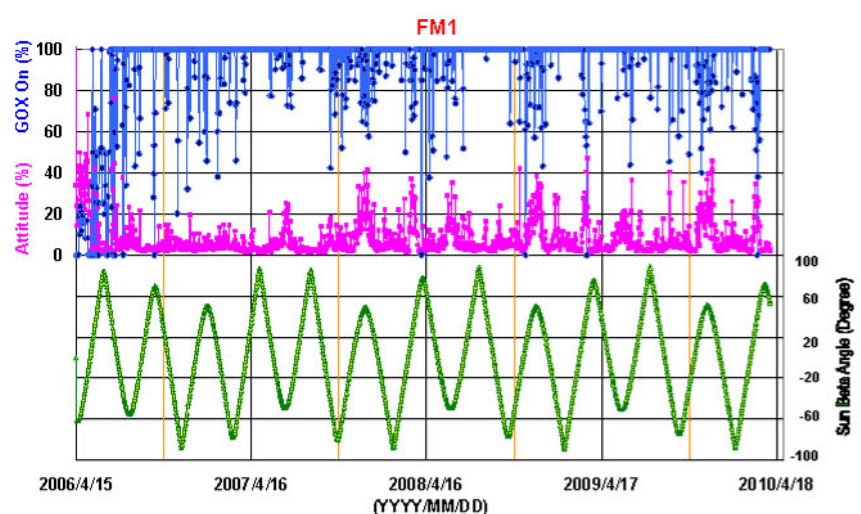

FM3

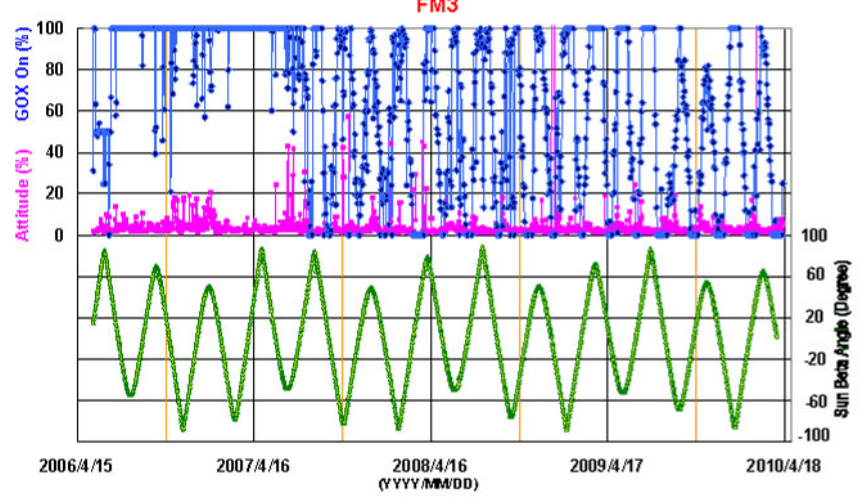

FM5

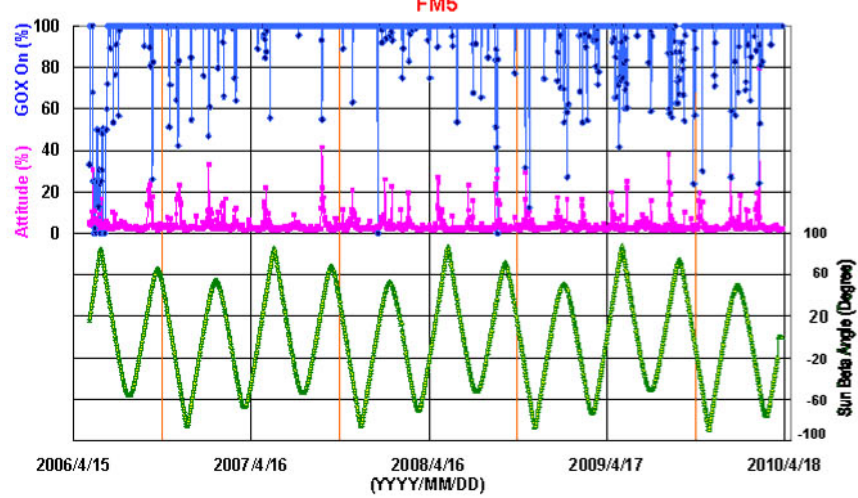

GOX ON (\%)

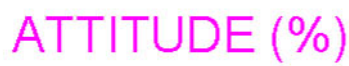

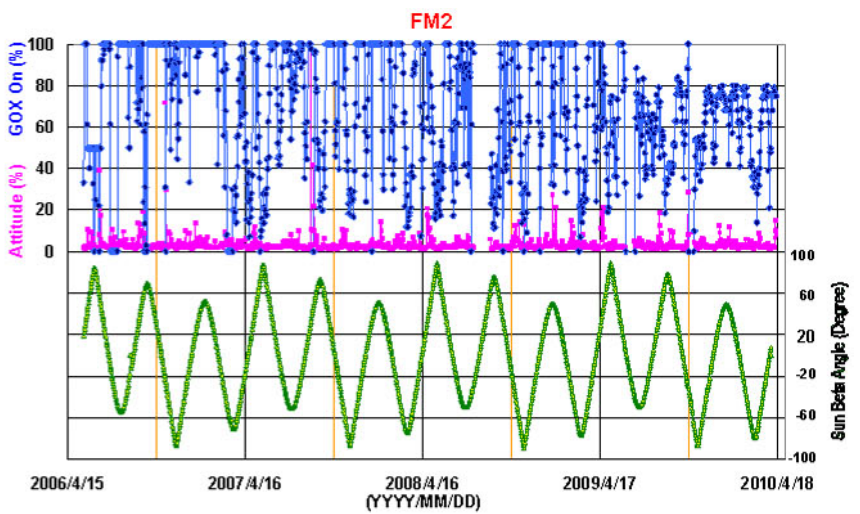
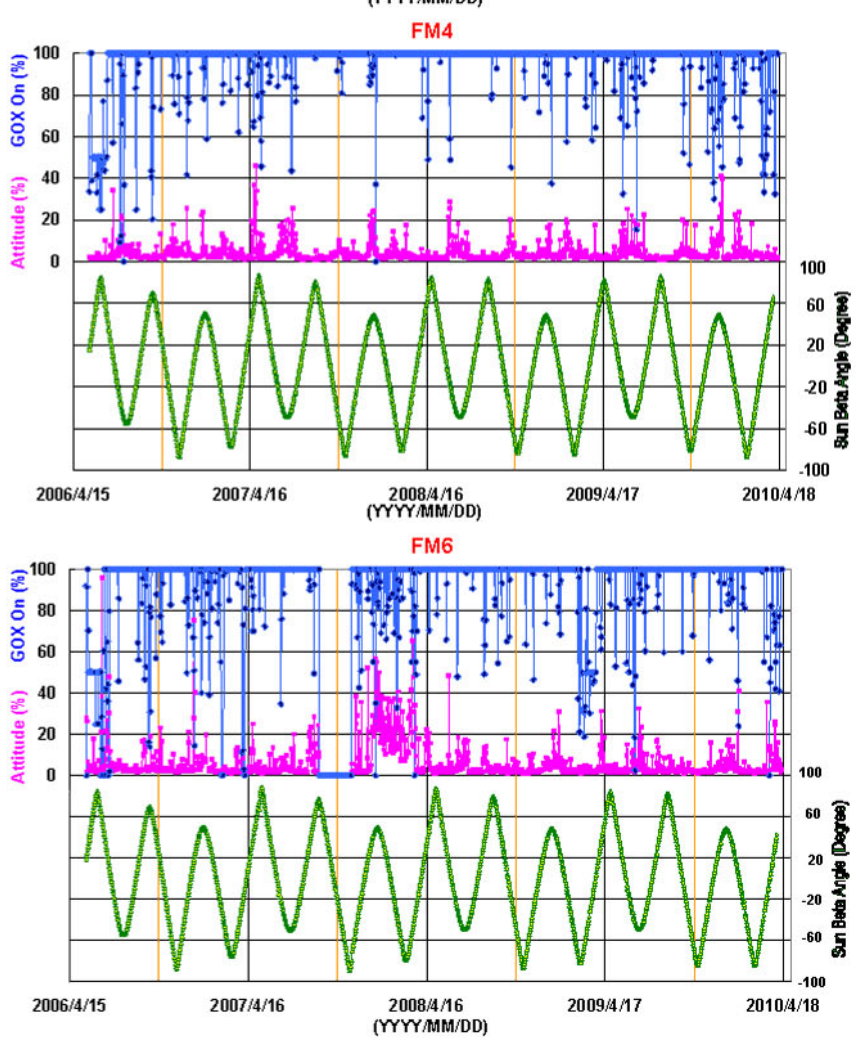

SUN BETA ANGLE (Degree)

Fig. 1. Spacecraft System Performance after Four Years in Orbit.

to migrate the experimental system into a stable and reliable operational system for follow-on missions.

The operation status of the key subsystems for all six satellites after four years in orbit is shown in Table 1. The battery power issue is a common and continuous major degradation problem for all spacecraft. For clarity, the satellites will be referred to as "FMx" where $\mathrm{x}$ is 1 to 6 . FM4 and FM6 are experiencing significant battery degradations that are causing the payloads to be powered off unexpectedly, even at high battery state-of-charge. In addition, FM2 experienced a sudden significant solar panel power shortage in
mid-November 2007. Since then, the output power of FM2 was reduced to one-half of the maximum solar array power capability, from $200 \mathrm{~W}$ to $100 \mathrm{~W}$. The root cause of the FM2 power shortage is still undetermined. FM3 encountered a solar array drive mechanism failure at $711 \mathrm{~km}$ orbit that prohibited the continuous thrust firing of the FM3. The other five FS-3/C satellites reached their final mission orbit altitude of $800 \mathrm{~km}$ by the end of November 2007 (Fong et al., 2008b). FM3 tracked the solar power at reduced duty cycle depending on the power status of the spacecraft. The secondary payloads, TIP and TBB, on FM2 and FM3, as shown 
Table 1. Mission Operation Status of Each Subsystem for All Six Spacecraft.

\begin{tabular}{|c|c|c|c|c|c|c|c|c|}
\hline S/C No. & $\begin{array}{l}\text { Operational } \\
\text { Mode }\end{array}$ & $\begin{array}{l}\text { Spacecraft } \\
\text { State }\end{array}$ & ADCS Mode & EPS Mode & C\&DH Mode & GOX & TIP & TBB \\
\hline FM1 & Normal & Normal & Fixed-Yaw & Normal & High Rate & Operating & $\begin{array}{l}\text { Low Beta } \\
\text { Operating }\end{array}$ & $\begin{array}{l}\text { Low Beta } \\
\text { Operating }\end{array}$ \\
\hline FM2 & Normal & $\begin{array}{l}\text { Power } \\
\text { Shortage } \\
\text { (Note 5) }\end{array}$ & Fixed-Yaw & Normal & High Rate & $\begin{array}{l}\text { Reduced } \\
\text { Duty-Cycle } \\
\text { Operating }\end{array}$ & $\begin{array}{l}\text { Off } \\
\text { (Note 1) }\end{array}$ & $\begin{array}{l}\text { Off } \\
\text { (Note 1) }\end{array}$ \\
\hline FM3 & $\begin{array}{l}\text { Normal } \\
@ 711 \mathrm{~km} \\
\text { (Note 3) }\end{array}$ & $\begin{array}{l}\text { SADA } \\
\text { Stuck } \\
\text { (Note 3) }\end{array}$ & Fixed-Yaw & Normal & High Rate & $\begin{array}{l}\text { Off } \\
\text { (Note 4) }\end{array}$ & $\begin{array}{l}\text { Off } \\
\text { (Note 1) }\end{array}$ & $\begin{array}{l}\text { Off } \\
\text { (Note 1) }\end{array}$ \\
\hline FM4 & Normal & $\begin{array}{l}\text { Battery } \\
\text { Degradation } \\
\text { (Note 2) }\end{array}$ & Fixed-Yaw & Normal & High Rate & Operating & $\begin{array}{l}\text { Low Beta } \\
\text { Operating }\end{array}$ & $\begin{array}{l}\text { Low Beta } \\
\text { Operating }\end{array}$ \\
\hline FM5 & Normal & Normal & Fixed-Yaw & Normal & High Rate & $\begin{array}{l}\text { Operating } \\
\text { (Low SNR) }\end{array}$ & $\begin{array}{l}\text { Low Beta } \\
\text { Operating }\end{array}$ & $\begin{array}{l}\text { Low Beta } \\
\text { Operating }\end{array}$ \\
\hline FM6 & Normal & $\begin{array}{l}\text { Battery } \\
\text { Degradation } \\
\text { (Note 2) }\end{array}$ & Fixed-Yaw & Normal & High Rate & $\begin{array}{l}\text { Operating } \\
\text { (Low SNR) }\end{array}$ & $\begin{array}{l}\text { Low Beta } \\
\text { Operating }\end{array}$ & $\begin{array}{l}\text { Low Beta } \\
\text { Operating }\end{array}$ \\
\hline
\end{tabular}

Note: 1. Secondary payloads are power off due to power shortage. 2: Significant FM4 \& FM6 battery degradations cause payload power off at high battery state-of-charge. 3: FM3 was kept at $711 \mathrm{~km}$ orbit due to stuck solar array drive. 4: FM3 has been in an abnormal condition (lost of communication) since July. 5: FM2 experienced a sudden solar panel power shortage with only one solar panel working. SADA = Solar Array Drive Assembly ADCS = Attitude Determination and Control Subsystem EPS $=$ Electrical Power Subsystem $\mathrm{C} \& \mathrm{DH}=$ Command and Data Handling Low Beta $=$ low sun beta angle.

in Table 1, have been powered off due to the power shortage issues. Furthermore, FM3 has been in a severe abnormal condition (much more frequent loss of communication and low power status) since July 2010 (Fong et al., 2010).

Figure 1 shows the spacecraft system performance observed over the past four years (since launch) for the GOX mission payload with the duty cycle on, and spacecraft ADCS (Attitude Determination and Control Subsystem) attitude performance vs. spacecraft sun beta angle. The sun beta angle is defined as the angle between the spacecraft orbital plane and the vector from the sun. It determines the percentage of time the spacecraft in low Earth orbit spends in direct sunlight, absorbing solar energy. The GOX payload should be on during the normal operation period except during the constellation deployment phase.

In Fig. 1, it is observed that all spacecraft continue to operate with the GOX payload duty cycle on at high percentage rates even as the spacecraft bus and payload start to show degradation. FM1 has provided good payload performance, however it shows worse attitude performance than the other spacecraft. FM2 started to show reduced GOX payload duty-cycle on operations due to a battery charging efficiencydecreased phenomena that was experienced after the satellite was recovered from lost communication in June 2009. FM3 encountered malfunctions of the solar array drive mechanism starting in August 2007 when it reached a $711 \mathrm{~km}$ orbit. FM3 has been kept at that altitude and the GOX payload has been operating at low duty cycle since then. FM4 performed very well during the four year operational period, but recently its battery has shown significant degradation. FM5 has provided good spacecraft performance, however its GOX payload shows low SNR problems resulting in difficulties generating useful data even when the GOX payload is on. FM6 has a similar GOX payload low SNR problem. In September 2007, FM6 experienced loss of communications for 67 days. The satellite resumed contact and recovered on its own after a computer master reset event occurred over the South Atlantic Anomaly (SAA) region. In summary, due to the batteries aging, four out of the six spacecraft have begun to encounter a battery degradation problem. FM4 and FM6 are worse than the other four spacecraft. The major on-orbit performance highlights for all spacecraft are summarized in Table 2.

\subsection{GOX mission payload performance}

Figure 2 shows the four-year statistics for the number of daily occultation events for (a) atmosphere profiles and (b) ionosphere profiles of electron density. The atmosphere and ionosphere occultation profiles contributed by each spacecraft are shown in Table 3.

The GOX payload performance summaries are shown in Table 4 . As the primary mission payload, four GOX instruments are being operated at a duty cycle of $100 \%$ and two 
Table 2. Spacecraft Constellation Performance Summary.

\begin{tabular}{|c|c|}
\hline S/C ID & Summary \\
\hline FM1 & $\begin{array}{l}\text { Bus GPSR GPS Non-Fixed -> Operation Solution } \\
\text { GOX RF1 (POD1/ANT0) Lower SNR -> GOX Reboot Loop -> GOX FB } 4.4 \text { Update } \\
\text { Payload Unexpected Off -> Battery Degradation } \\
\text { Bad Attitude }\end{array}$ \\
\hline FM2 & $\begin{array}{l}\text { BCR dMdC Charge Algorithm Issue -> FSW Update } \\
\text { Solar Array Power Shortage -> Reduced GOX Operation } \\
\text { GOX Reboot Loop -> GOX FB } 4.4 \text { Update } \\
\text { Battery Pressure Difference Anomaly -> FSW Update } \\
\text { PCM DC Converter Abnormally Off -> TBB \& TIP Off } \\
\text { Loss of Communication -> Auto Recovery }\end{array}$ \\
\hline FM3 & $\begin{array}{l}\text { Loss of Communication -> Auto Recovery } \\
\text { Solar Array Driver Lockout -> Reduced GOX Operation } \\
\text { Bus GPSR GPS Non-Fixed -> Operation Solution } \\
\text { GOX RF1 (POD1/ANT0) Lower SNR -> GOX Reboot Loop -> GOX FB 4.4 Update } \\
\text { Payload Unexpected Off -> Battery Degradation }\end{array}$ \\
\hline FM4 & $\begin{array}{l}\text { Bus GPSR GPS Non-Fixed (since Launch)-> Operation Solution } \\
\text { GOX RF1 (POD1/ANT0) Lower SNR -> GOX Reboot Loop -> GOX FB } 4.4 \text { Update } \\
\text { Payload Unexpected Off -> Battery Degradation -> On-Orbit Battery Refreshment }\end{array}$ \\
\hline FM5 & $\begin{array}{l}\text { GOX RF1 (POD1/ANT0) Lower SNR -> GOX Reboot Loop -> GOX FB } 4.4 \text { Update } \\
\text { GOX RF4 (OCC1/ANT3) SNR Decreasing-> Operation Solution } \\
\text { Bus GPSR degraded -> Operation Solution } \\
\text { Payload Unexpected Off -> Battery Degradation -> On-Orbit Battery Refreshment }\end{array}$ \\
\hline FM6 & $\begin{array}{l}\text { Loss of Communication }->->\text { Auto Recovery } \\
\text { Bus GPSR GPS Non-Fixed -> Operation Solution } \\
\text { GOX RF1 (POD1/ANT0) Lower SNR -> GOX Reboot Loop -> GOX FB 4.4 Update } \\
\text { GOX SNR decreasing at High Temp. -> Auto Recovery } \\
\text { Payload Unexpected Off -> Battery Degradation -> On-Orbit Battery Refreshment } \\
\text { Orbit Raise-Up -> Under Investigation }\end{array}$ \\
\hline
\end{tabular}

Note: GPSR = GPS Receiver, RF1 = Radio Frequency No. 1, Ant0=Antenna No. 0, POD = Precision Orbit Determination, FB = Firmware Build, BCR = Battery Charge Regulator $\mathrm{dMdC}=$ Derivative of Battery Molecular to Charge, FSW = Flight Software, RF4 = Radio Frequency No. 4, Ant $3=$ Antenna No. 3 , OCC1 = Occultation No. 1.

\section{Atmospheric}

\section{Total 2,116,936 since launch}

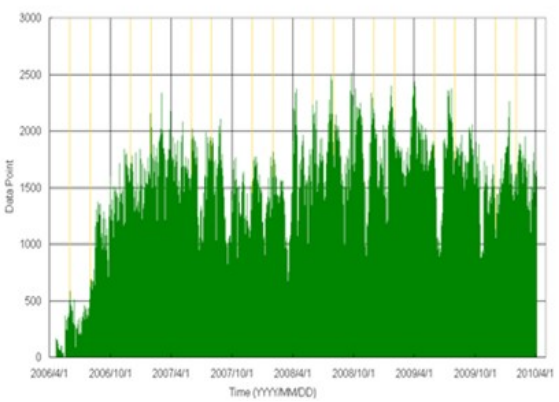

\section{Ionospheric}
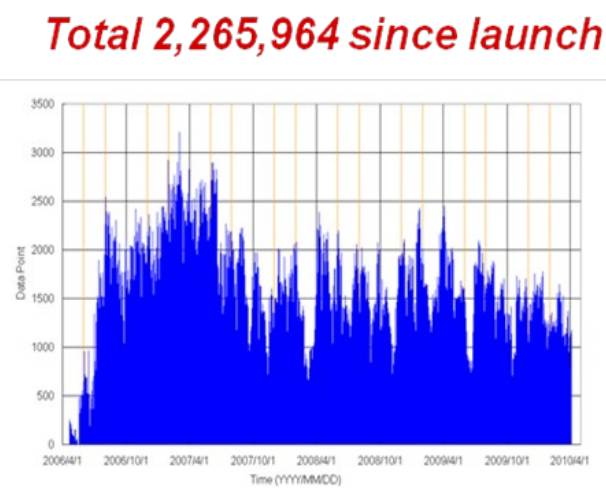

Fig. 2. Four-Year Statistics Showing the Number of Daily Occultation Events (as-of-4/5/2010) for (a) atmosphere Profiles, and (b) ionosphere Profiles of Electron Density. 
Table 3. Number of Occultation Profiles for Each GOX Instrument after Four Years in Orbit.

\begin{tabular}{lrrrrrrr}
\hline Atmosphere & FM1 & FM2 & FM3 & FM4 & FM5 & FM6 & Total \\
\hline Operation Duration & 1397 & 1282 & 1173 & 1424 & 1401 & 1302 & 7979 \\
Atmosphere Profiles Per Day & 285.07 & 229.48 & 242.94 & 333.37 & 248.73 & 242.96 & 1582.55 \\
Total Atmosphere Profiles & 398245 & 294198 & 284970 & 474713 & 348475 & 316335 & 2116936 \\
\hline Ionosphere & FM1 & FM2 & FM3 & FM4 & FM5 & FM6 & Total \\
\hline Operation Duration & 1293 & 1284 & 1173 & 1423 & 1286 & 1300 & 7759 \\
Ionosphere Profiles Per Day & 284.65 & 275.74 & 292.71 & 394.54 & 241.03 & 253.17 & 1741.84 \\
Total Ionosphere Profiles & 368049 & 354054 & 343353 & 561426 & 309966 & 329116 & 2265964 \\
\hline
\end{tabular}

other GOX instruments (onboard FM2 and FM3) are being operated based on the state of the power charge at various sun beta angles (due to the power shortages). There are many factors that affect the quality of the occultation data received from the GPS signals. Among them, the low SNR on the occulting precision orbit determination (POD) antenna seems to affect the data quality the most. In this mission the POD antenna has two functions: precision orbit determination, and ionospheric radio occultation processing. The occultation antenna is only used for atmospheric radio occultation processing. Four spacecraft (FM1, FM3, FM5, and FM6) have exihibited a low SNR anomaly on the POD1 antenna for the GOX payload. FM2 exhibited a low SNR anomaly on POD2.

In February 2009, the FM6 GOX payload SNR decreased, however, the GOX payload operating temperature was not over the red high limit (the limit that will shut down the GOX payload power autonomously). The RO profiles decreased to less than 100 per day and FM6 could only generate good RO data while the operating temperature was less than $25^{\circ} \mathrm{C}$. After two months of low RO data generation, the spacecraft was flip-flopped and the FM6 GOX payload recovered on its own and began to operate at full duty cycle. "Flip-flop" means the spacecraft is rotated 180 degrees around the nadir (yaw) axis when the spacecraft sun beta angle is changed to 0 degrees, approximately every 57 days. This design allows the solar array to be reduced to half of the required size when compared to a design that does not "flip-flop".

\subsection{Spacecraft payload on/off performance}

The causes of the GOX payload being powered off are categorized as follows: nadir mode due to attitude excursion; stabilized mode after thrust burns; processor reboot/resets; entrance to stabilized/safehold mode; power shortage; derivative of battery molecular to charge (dMdC) anomaly; nadir mode after thrust burns such that spacecraft enters into power contingency; and Power Control Module (PCM) Direct Current (DC) Off anomaly. From the GOX payload duty cycle on values shown in Fig. 1, it is possible to compile the GOX payload duty cycle on statistics for one to four years, which are shown in Fig. 3. It is observed that the FM2 and FM3

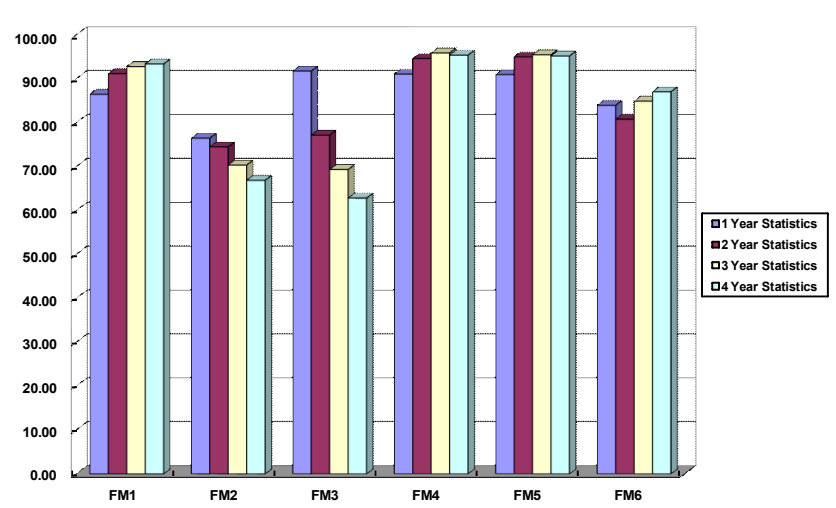

Fig. 3. GOX Payload Duty Cycle On Statistics for One to Four Years.

power shortages are the main cause of the degraded average GOX duty cycles on those spacecraft. After the completion of the orbit transfer, FM4 and FM5 demonstrate the best GOX payload performance. The drop in FM6 GOX payload duty cycles in the second year is due to the complete loss of communications for 67 days. Additionally, the low SNR issue makes FM6 the 4th best performing satellite among the 6 satellites, following FM4, FM1, and FM5 for GOX payload performance.

\subsection{Spacecraft Ni-H2 battery performance}

There is another payload off phenomenon that did not belong to any category listed in the previous sub-section that is relevant to the battery performance degradation issue. Beginning in April 2009, the operations team has observed the GOX payload unexpectedly turn off while the spacecraft has good power and attitude conditions, where the battery stateof-charge (SOC) indicated is higher than the design value of 5.5 ampere-hours, and the spacecraft is operating nominally at the Nadir-Yaw mode. This phenomenon is beginning to be a frequently recurring event on all six spacecraft. According to the spacecraft design, the payload will be turned off only when any of the following design conditions 
Table 4. GOX Payload Performance Summaries.

\begin{tabular}{|c|c|c|c|c|c|c|}
\hline $\begin{array}{l}\text { S/C } \\
\text { No. }\end{array}$ & $\begin{array}{l}\text { GOX } \\
\text { Duty } \\
\text { Cycle }\end{array}$ & $\begin{array}{l}\text { POD1 } \\
\text { RF1 } \\
\text { ANT0 }\end{array}$ & $\begin{array}{l}\text { POD2 } \\
\text { RF2 } \\
\text { ANT1 }\end{array}$ & $\begin{array}{l}\text { OCC2 } \\
\text { RF3 } \\
\text { ANT2 }\end{array}$ & $\begin{array}{l}\text { OCC1 } \\
\text { RF4 } \\
\text { ANT3 }\end{array}$ & $\begin{array}{l}60 \text { day } \\
\text { Average } \\
\text { Data } \\
\text { Profile } \\
\text { (Mean/Peak) }\end{array}$ \\
\hline FM1 & $100 \%$ & $\begin{array}{l}\text { Low } \\
\text { SNR }\end{array}$ & Normal & Normal & Normal & $290 / 350$ \\
\hline FM2 & $\begin{array}{l}80 \%-> \\
60 \%\end{array}$ & Normal & Normal & Normal & Normal & $200 / 320$ \\
\hline FM3 & $\begin{array}{l}60 \%-> \\
36 \%\end{array}$ & $\begin{array}{l}\text { Low } \\
\text { SNR }\end{array}$ & Normal & Normal & Normal & $150 / 300$ \\
\hline FM4 & $100 \%$ & Normal & Normal & Normal & Normal & $300 / 420$ \\
\hline FM5 & $100 \%$ & $\begin{array}{l}\text { Low } \\
\text { SNR }\end{array}$ & $\begin{array}{l}\text { Low } \\
\text { SNR }\end{array}$ & Normal & $\begin{array}{l}\text { Low } \\
\text { SNR }\end{array}$ & $160 / 310$ \\
\hline FM6 & $100 \%$ & $\begin{array}{l}\text { Low } \\
\text { SNR }\end{array}$ & Normal & Normal & $\begin{array}{l}\text { Low } \\
\text { SNR }\end{array}$ & $130 / 300$ \\
\hline
\end{tabular}

Note: POD1 = Precision Orbit Determination No. 1, POD2 = Precision Orbit Determination No. 2, OCC1 = Occultation No. 1 , OCC2= Occultation No. 2 ; RF1 = Radio Frequency No. 1, RF2 = Radio Frequency No. 2, RF3 = Radio Frequency No. 3, RF4=Radio Frequency No. 4; and Ant0=Antenna No. 0, Ant1=Antenna No. 1, Ant2=Antenna No. 2, Ant3 = Antenna No. 3 .

are met: (1) the external payload off ground command is sent; (2) the low power spacecraft battery SOC falls below 5.5 ampere-hours; (3) three flight computers (Attitude Control Electronics (ACE), Battery Control Regulator (BCR), or Flight Computer (FC)) have been rebooted or reset; or (4) the spacecraft attitude has entered into stabilize/safehold/thrust mode.

The battery performance degradation issue has become one of the major triggers of the unexpected payload off phenomenon. The unexpected payload off is categorized as a deviation from the normal payload off that is initiated by either (1) the ground command or (2) autonomous internal command due to insufficient solar power charge to the battery. The S-band transmitter is turned on and needs to draw a substantial amount of power and current with a higher demand priority from the bus during a ground Telemetry Tracking and Control (TT\&C) pass. This lowers the bus voltage further if the battery cannot provide sufficient power in time. Consequently, the battery degradation effect may cause the payload to be turned off sometimes during a ground TT\&C pass. The battery degradation, as observed, has shown to cause the bus voltage to be lower than 11 Volts (compared to the nominal 14 Volts), but slightly higher than 10 Volts. Since the input voltage requirement for the tank pressure transducer is above 11 Volts, the pressure transducer reading will decrease dramatically and become unreliable to reflect the low bus voltage status when the actual bus voltage falls below 11 Volts. In addition, when the value of bus voltage is below the Power Control Module (PCM) design value of
10 Volts, the payload will be turned off by the PCM internal command due to the internal under voltage protection circuit design (Fong et al., 2010).

Table 5 shows the average variation rate per year of the battery for each spacecraft. FM4 and FM6 have shown the worst battery degradation. The spacecraft battery degradation significantly impacts the spacecraft operational life and the total number of GOX payload occultation profiles.

\section{Ground system performance}

\subsection{NSPO ground systems}

NSPO was in charge of the mission operations of FS-3/C after launch including the early orbit checkout and initialization, constellation orbit deployment, and normal and contingent satellite operations. The facility used for the mission operations is the SOCC located in Hsin-Chu, Taiwan. The SOCC includes four subsystems: (1) Mission Operation subsystem for the real-time satellite operations during station contact; (2) Flight Dynamics Facility for the orbit determination, prediction and maneuver planning; (3) Science Control subsystem for the science data preprocessing; and (4) Mission Control subsystem for the operation planning and command scheduling. NSPO also provides two TT\&C stations, (typically called ground stations) in Taiwan to support the contingent operations of FS-3/C.

In the early orbit checkout phase, the SOCC successfully sent commands to FS-3/C for spacecraft State of Health 
Table 5. Average Variation Rate per Year of Each Spacecraft Battery.

\begin{tabular}{cllllll}
\hline $\begin{array}{c}\text { S/C } \\
\text { ID }\end{array}$ & $\begin{array}{l}\text { Batt V } \\
\text { Mean [V] }\end{array}$ & $\begin{array}{l}\text { Batt V } \\
\text { Min [V] }\end{array}$ & $\begin{array}{l}\text { Batt SOC } \\
\text { Max [Ah] }\end{array}$ & $\begin{array}{l}\text { Batt SOC } \\
\text { Min [Ah] }\end{array}$ & $\begin{array}{l}\text { PL Off } \\
\text { SOC }\end{array}$ & Remarks \\
\hline FM1 & -0.034 & -0.104 & 1.169 & -0.657 & $\sim 1.95$ & $\begin{array}{l}\text { Battery degradation } \\
\text { since 2008/4 } \\
\text { Battery over pressure }\end{array}$ \\
\hline FM2 & -0.031 & -0.159 & -0.236 & -0.036 & $\sim 1$ & $\begin{array}{l}\text { Battery degradation } \\
\text { since 2008/10 } \\
\text { Battery charging } \\
\text { efficiency decreased }\end{array}$ \\
\hline FM3 & -0.094 & -0.080 & 0.769 & 0.127 & $\sim 0.45$ & $\begin{array}{l}\text { Battery degradation } \\
\text { since 2008/10 }\end{array}$ \\
\hline FM4 & -0.060 & -0.319 & 0.453 & 0.628 & $\sim 2.5$ & $\begin{array}{l}\text { Battery degradation } \\
\text { since 2007/12 } \\
\text { Battery over pressure }\end{array}$ \\
\hline FM5 & -0.026 & -0.122 & 0.617 & 0.596 & $\sim 1.95$ & $\begin{array}{l}\text { Battery degradation } \\
\text { since 2008/1 }\end{array}$ \\
\hline FM6 & -0.042 & -0.249 & 1.213 & 1.184 & $\sim 2.5$ & $\begin{array}{l}\text { Battery degradation } \\
\text { since 2007/12 } \\
\text { Battery over pressure }\end{array}$ \\
\hline
\end{tabular}

Note: PL = Payload.

(SOH) inspection and hardware/software initialization. The measured performance of the in-orbit spacecraft compared to the expected results from the relevent ground tests show the SOH of a specarft in orbit. Some components, such as the GPS receiver and the battery charging parameters, were reconfigured for improved performance. In the constellation orbit deployment phase, the six FS-3/C satellites were maneuvered into the mission orbit altitude one by one in a planned time sequence. Each satellite took 4-6 weeks to maneuver into its mission orbit. The satellite constellation was fully deployed in 19 months. After the deployment, five of the six satellites had successfully reached the predefined mission orbits (except the FM3 whose onboard propulsion function was degraded which prohibited it from reaching its final mission orbit altitude).

In the normal operations phase, the SOCC routinely uplinked the time-tagged command loads to the satellites so that for each scheduled station contact, the satellites would sequentially turn on their transmitter, downlink payload data, downlink SOH data and then turn off their transmitter. On average, there are approximately 80 station contacts per day to dump the onboard payload data for near real-time meteorological research and operational applications. During normal operations some satellite anomalies also occurred, such as FC computer resets, BCR computer resets, ACE computer resets, Master resets and Phoenix resets. Phoenix is an off state of the satellite when satellite is out of battery power and is used to support satellite recovery when power condition is back to stable. Each type of reset was recovered by sending a series of configuration commands so that both the satellite and payload could resume normal operation as soon as possible.

All six satellites have experienced some anomalies in the electric power subsystem and/or payload instrument performance causing onboard electronic power shortages and payload duty-cycle reduction. The SOCC and the operation team used operational methods to reduce the impacts of the anomalies and increase the payload data output. It has proven difficult to maintain the FS-3/C constellation in the current $\mathrm{SOH}$ status after four years in operation.

\subsection{NOAA ground systems}

When FS-3/C was launched, ground station support was contracted with the Universal Space Network (USN) through their stations at Poker Flats, Alaska and Kiruna, Sweden. USN performed very well for $2 \mathrm{yr}$, but in an effort to reduce operational costs NOAA made a decision to employ indigenous resources. NOAA assets were established for FS-3/C at Fairbanks Command \& Data Acquisition Station (FCDAS) as well as Wallops Command \& Data Acquisition Station (WCDAS), and services were contracted with Kongsberg Satellite Services (KSAT) at their Troms $\varnothing$ Satellite Station through NOAA agreements with the Norwegian Space Centre. Since April 2008, NOAA stations have been providing both uplink and downlink services and Troms $\varnothing$ has been 
providing downlink services only. Ground station support availability for $\mathrm{FS}-3 / \mathrm{C}$ was required to perform at $90 \%$ or better. Over the course of FS-3/C operations, ground stations services have performed at $95 \%$ or better with only minor interruptions due to occasional equipment issues (hung servers or processors, for example).

FS-3/C command uplink and telemetry downlink activities are coordinated by the NSPO SOCC with the Remote Tracking Stations (RTS). Once upcoming FS-3/C passes have been deconflicted with other ground station activities, SOCC generates spacecraft ephemeris, spacecraft command uploads and ground schedules and distributes the files to the ground stations. All contacts with the spacecraft are established and conducted autonomously via schedules executed at the SOCC and the RTS, with the exception of any realtime commanding conducted by Mission Control personnel at SOCC. During the pass, the spacecraft and ground system are autonomously monitored by SOCC as the data stored on the spacecraft is downlinked to the ground station. After the spacecraft contact has ended, all connections are autonomously terminated and the RTS data server forwards the Contact Report to the SOCC as well as the Payload Data Files to the Data Processing Centers for processing.

FS-3/C mission data is distributed from data servers at the ground stations across the world wide web via Secure File Transfer Protocol (SFTP) to the SOCC and CDAAC. Figure 4 shows the flow of data between the RTS, SOCC and CDAAC. One week prior to real-time, the spacecraft ephemerides (2 line element sets) and RTS pass schedules are made available to the mission team for operations. Timeliness can vary but SFTP has been found to be a very reliable and inexpensive means for distributing the data globally. A typical post contact scenario consists of transferring realtime and non-real-time spacecraft data to SOCC, followed by the transfer of mission files to CDAAC and then to SOCC. Statistics show that mission data arrives at CDAAC for processing within 15 min after spacecraft loss of signal (LOS), which is the end of the scheduled spacecraft contact with the ground station, $97 \%$ of the time.

\subsection{Science data processing}

The COSMIC Data Analysis and Archival Center (CDAAC) at UCAR currently processes COSMIC data in near real-time for operational weather centers and the research community. The CDAAC also reprocesses RO data in a more accurate post-processed mode (within 6 weeks of observation) for COSMIC and other missions such as GPS/MET, CHAMP, SAC-C, GRACE, TerraSAR-X, (and METOP/GRAS in the near future). The data processing at the CDAAC includes: GPS site coordinate and zenith tropospheric delay (ZTD) estimation for a global ground-based reference network, high-rate (30 s) GPS satellite clock estimation, LEO precision orbit determination, computation of L1 and L2 atmospheric excess phases (Schreiner et al., 2009), retrieval of neutral atmospheric bending angles and refractivity for each LEO occultation event (Kuo et al., 2004), estimation of absolute total electron content (TEC), and retrieval of electron density profiles (Schreiner et al., 1999). The CDAAC also provides COSMIC TIP calibrated radiance products. All COSMIC products are made available freely to the community at www.cosmic.ucar.edu.

Since the launch of the FS-3/C constellation in April 2006, COSMIC has provided a large amount of valuable science data to the operational and research communities. As of 1 September 2010, COSMIC and CDAAC have produced over 2.5 million high quality neutral atmospheric and ionospheric sounding profiles, over 2.6 million absolute TEC data arcs, S4 scintillation observations, over $16000 \mathrm{~h}$ of quality controlled TIP radiances, and a significant (but not centrally archived) amount of ground-based TBB observations. On average, COSMIC currently produces around 1000 GPS-RO soundings per day. Approximately ninety percent of these are processed and delivered via the Global Telecommunications System (GTS) to operational centers within three hours. The remaining ten percent have higher latency due to the satellites' inability to downlink every orbit ( $\sim 100 \mathrm{~min})$. The COSMIC RTSs are down-linking and forwarding the payload data to the CDAAC in less than $15 \mathrm{~min}$ on average. The CDAAC processes a single dump of payload data into profiles and forwards them to the GTS via NOAA in less than $10 \mathrm{~min}$. The average latency of COSMIC data is currently approximately $90 \mathrm{~min}$ for single orbit dumps. The reliability of the RTS stations and the CDAAC near real-time processing system have been measured at greater than $95 \%$ and $99.5 \%$, respectively.

\section{Lessons learned from encountered technical challenges}

This section contains highlights of some major challenges encountered and enhancements accomplished after twentyfour satellite-years ( $4 \mathrm{yr} \times 6$ satellites) of operation in orbit of the FS-3/C mission. There are many lessons learned from the four years of operations, which can be used to improve similar future missions (Fong et al., 2008a,b,c, 2009a,b).

\subsection{Mission lessons learned}

Table 6 highlights three major mission lessons learned. They are: (1) the determination of the spacecraft communication frequency, (2) the prevention of the Radio Frequency Interference (RFI) among the three different payloads in each spacecraft, and (3) the quantity definition of the radio occultation profiles.

\subsection{Payload lessons learned}

The GOX payloads are performing well and reliabily at the instrument level based on the assessment of the available data 


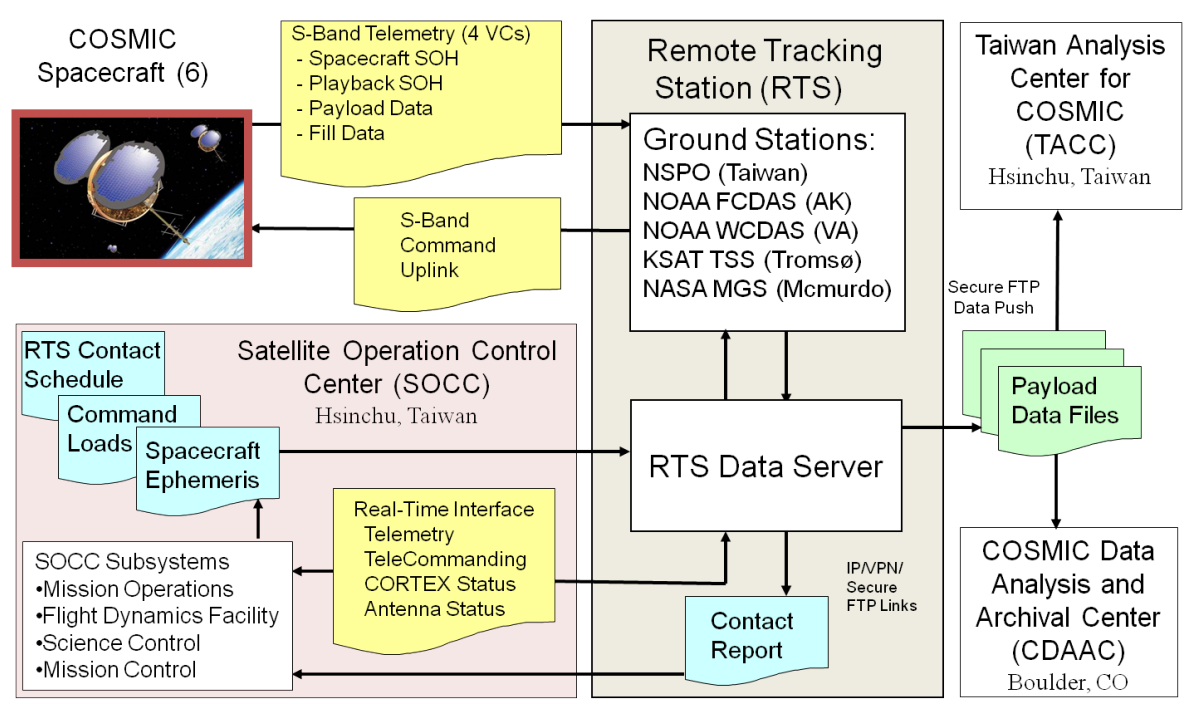

Fig. 4. FS-3/C Ground System Data Flow.

Table 6. Mission Lessons Learned.

\begin{tabular}{|c|c|c|c|}
\hline Items & Implementation & Observation/Major finding & Lessons learned \\
\hline $\begin{array}{l}\text { RFI Among } \\
\text { Payloads }\end{array}$ & $\begin{array}{l}\text { - RFI was not tested at the space- } \\
\text { craft system level to identify } \\
\text { the interference severity on the } \\
\text { ground }\end{array}$ & $\begin{array}{l}\text { - RFI was tested until on-orbit } \\
\text { - GOX L2 signals interfered with } \\
\text { VHF\&L bands on TBB ALL- } \\
\text { ON mode } \\
\text { - Consequently, TBB reduced its } \\
\text { operations at 2-band mode only }\end{array}$ & $\begin{array}{l}\text { - Frequency selection shall be co- } \\
\text { ordinated in the feasibility study } \\
\text { phase and reviewed by all par- } \\
\text { ties (mission, science, payload } \\
\text { provider, bus provider) }\end{array}$ \\
\hline $\begin{array}{l}\text { Radio Occul- } \\
\text { tation Profiles }\end{array}$ & $\begin{array}{l}\text { - Mission requirement is set at } \\
2500 \text { occultation profiles per day } \\
\text { on average based on the esti- } \\
\text { mate from a "near-perfect" con- } \\
\text { stellation situation }(\sim 3000 \text { pro- } \\
\text { files per day) }\end{array}$ & $\begin{array}{l}\text { - Two major factors seem to be } \\
\text { under-estimated: (1) PL down } \\
\text { time (2) data filtered out by data } \\
\text { quality control (for example: low } \\
\text { SNR, etc.) }\end{array}$ & $\begin{array}{l}\text { - The flow-down of mission re- } \\
\text { quirements shall be carefully im- } \\
\text { plemented in the success criteria } \\
\text { and shall consider the downtime } \\
\text { for each segment } \\
\text { - Improved S/C performance } \\
\text { - Improved PL performance } \\
\text { - Improve ground processing } \\
\text { software }\end{array}$ \\
\hline
\end{tabular}

Note: PL = Payload. 
as discussed in Sect. 3.2. However, there are some lessons learned from the observed GOX performance at the payload subsystem level. The major lessons learned from the data assessment at the GOX payload subsystem level, as summarized in Table 7, are: (1) GOX POD low SNR problem, (2) GOX OCC low SNR problem, and (3) GOX SNR decrease at high temperature.

\subsection{Spacecraft system lessons learned}

The spacecraft state of health correlates directly to the payload performance. The FS-3/C spacecraft is a modified version of a heritage design of the successful ORBCOMM spacecraft. However, the FS-3/C spacecraft, a micro-grade spacecraft $(<100 \mathrm{~kg})$, is not equipped with full comprehensive redundancy for avoiding single critical failure in design and/or high reliability components in critical instruments for durability. Five major spacecraft system lessons learned, as described in Table 8, are: (1) SSR (Solid State Recorder)/MIU (Mission Interface Unit) GOX data dropouts, (2) spacecraft design philosophy, (3) spacecraft downtime, (4) computer resets/reboots, and (5) ADCS (Attitude Determination and Control Subsystem) performance.

\section{Design improvements for the follow-on system}

\subsection{Mission trades and improvements}

In order to apply the lessons learned from the FS-3/C program to create an operational constellation, several mission trades have been studied. The results of the FS-7/C-2 mission trade studies are summarized in Fig. 5 (Fong et al., 2010; Yen, 2010; Yen and Fong, 2009).

The FS-7/C-2 satellites will be equipped with the nextgeneration GNSS-RO receiver (TriG) to collect more soundings per receiver. The TriG will have the ability to track GPS, Galileo and GLONASS GNSS systems, which includes 29 operational GPS satellites, 18 planned GLONASS, and 30 planned GALILEO satellites. The TriG mission payload receiver will have the capability to receive the GPS L1/L2/L5 signals, the GALILEO E1/E5/E6 signals, and the GLONASS L1/L2/L5 signals. This payload instrument will significantly improve the amount of data collected, which will lead to improved mission applications.

Figure 6 depicts the proposed FS-7/C-2 mission architecture. The FS-7/C-2 program is planned to have 12 satellites, which will result in collecting 8000 profiles per day. The mission baseline includes 6 satellites at low-inclination-angle orbit and 6 satellites at high-inclination-angle orbit so that the mission will collect more data from the low latitudes over what is currently being collected. Participants on the joint program will work together on the data processing and data utilization to improve the data processing aspect of the system.

\subsection{Spacecraft trades and improvements}

The FS-7/C-2 spacecraft will have improved payload performance, better attitude performance, simplified operation, simplified orbit transfer, increased data storage, and modular design for additional compatible science payloads. The spacecraft bus design intended for the follow-on system vs. the current FS-3/C bus design is shown in Table 9.

NSPO is responsible for the acquisition and management of the spacecraft for the FS-7/C-2 Program. The acquisition goal is to acquire the twelve (12) spacecraft along with the spacecraft design, information on the development, manufacture, assembly, integration, testing, and operations from a spacecraft contractor through a procurement contract. NSPO will integrate the mission payloads onto the contractor-provided spacecraft and perform the required integral system testing at NSPO. Additionally, it is planned that the spacecraft contractor will provide the necessary support to the integral integration and test (I\&T) at NSPO, and the launch site operations. The satellite (including spacecraft and payload) major milestones will be developed to incorporate the spacecraft development along with the subsequent production schedule of the spacecraft contractor and the integral satellite I\&T at NSPO to meet the intended launch periods as illustrated in the NSPO-NOAA Joint Program Integrated Master Schedule.

NSPO also plans to develop an additional NSPO selfreliant spacecraft along with the RO mission payload to be launched during the second launch of the joint mission. NSPO will be responsible for the system/subsystem design that will meet the satellite System Performance Requirements and perform the integral satellite I\&T and the launch site preparation activities.

\subsection{Ground trades and improvements}

The biggest and probably most challenging improvement for the next generation ground system will be meeting the objective latency requirement of $15 \mathrm{~min}$. FS-7/C-2 threshold latency of $45 \mathrm{~min}$ is expected to be easily achievable with twice per orbit data dumps in each orbit plane and will be a great improvement over FS-3/C latency. Meeting the objective latency of $15 \mathrm{~min}$ is more difficult to achieve. Data recovery trades are currently being evaluated as part of the FS-7/C-2 mission definition to determine feasibility versus affordability.

A ground system solution for FS-7/C-2 that will meet threshold latency requirements will likely employ 10 to 12 ground stations, 2 at each of the poles and 6 to 8 around the equator, to capture data from satellites in both orbit planes. The high-inclination orbit plane will be supported by the existing polar sites at Fairbanks, Wallops, Troms $\varnothing$, and McMurdo, and will require an additional station inside the Antarctic Circle to complement McMurdo. For the low-inclination orbit plane, a host of new equatorial ground 
Table 7. Payload lessons learned.

\begin{tabular}{|c|c|c|c|}
\hline Items & Implementation & Observation/Major finding & Lessons learned \\
\hline $\begin{array}{l}\text { GOX POD } \\
\text { Low SNR } \\
\text { Problem }\end{array}$ & $\begin{array}{l}\text { - After GOX payload instru- } \\
\text { ment, POD antenna ca- } \\
\text { ble link, and the POD an- } \\
\text { tenna are assembled into } \\
\text { the spacecraft, there is } \\
\text { no sufficient system level } \\
\text { ground testing during sys- } \\
\text { tem level I\&T }\end{array}$ & $\begin{array}{l}\text { - RF1 low SNR anomaly in lower } \\
\text { beta angle. First happened to } \\
\text { FM6 (2007-041), then FM1 } \\
\text { (2007-261), FM5 (2007-302), } \\
\text { and FM3 (2008-245). Only FM2 } \\
\text { \& FM4 RF1 has no SNR problem } \\
\text { - FM4 RF2 had low SNR problem } \\
\text { since 2010-071, so FM4 now use } \\
\text { RF1 only } \\
\text { - FM5 RF2 started to show low } \\
\text { SNR problem since } 2010-160 \text { in } \\
\text { lower beta angle (< 15 degree). } \\
\text { If RF2 decays like RF1 did, FM5 } \\
\text { GOX will generate no OCC data }\end{array}$ & $\begin{array}{l}\text { - Should conduct reversed } \\
\text { engineering to find the true } \\
\text { cause of the problem } \\
\text { - Should conduct adequate } \\
\text { SNR test/measurement at } \\
\text { the system level during the } \\
\text { ground testing in future } \\
\text { similar programs }\end{array}$ \\
\hline $\begin{array}{l}\text { GOX OCC } \\
\text { Low SNR } \\
\text { Problem }\end{array}$ & $\begin{array}{l}\text { - GOX instrument, OCC ca- } \\
\text { ble link, and the OCC an- } \\
\text { tenna may not be } \\
\text { adequately modeled for } \\
\text { thermal analysis for SNR } \\
\text { sensitivity variations over } \\
\text { the intended temperature } \\
\text { range and the anticipated } \\
\text { orbital conditions }\end{array}$ & $\begin{array}{l}\text { - FM5 RF4 low SNR in high beta } \\
\text { angle while GOX temp }>40 \text { deg C } \\
\text { - Started from 2008-082 when- } \\
\text { ever in higher beta angle period } \\
\text { (|Beta }>40 \text { degree) } \\
\text { - Higher minus beta angle has neg- } \\
\text { ative impact to the RO observed } \\
\text { occultations number while RF4 is } \\
\text { the setting antenna } \\
\text { - FM6 RF4 unstable and } \\
\text { SNR drops periodically } \\
\text { (2009-032 2009-105, 2009- } \\
\text { 151 2009-192, 2010-141 now) }\end{array}$ & $\begin{array}{l}\text { - Ground commands to tem- } \\
\text { porarily operate the space- } \\
\text { craft at the fixed SADA } \\
\text { configuration are able to } \\
\text { cool down the GOX tem- } \\
\text { perature below } 35 \text { degree C } \\
\text { when beta }<-50 \text { degree } \\
\text { - The payload thermal re- } \\
\text { quirement and the related } \\
\text { thermal analysis/testing } \\
\text { should be properly } \\
\text { implemented }\end{array}$ \\
\hline $\begin{array}{l}\text { GOX SNR } \\
\text { Decrease at } \\
\text { High } \\
\text { Temperature }\end{array}$ & $\begin{array}{l}\text { - Since 2009-035, FM6 SNR } \\
\text { dropped; the RO profiles } \\
\text { decreased to less than } 100 \text {, } \\
\text { FM6 only can generate } \\
\text { good RO while GOX temp } \\
\text { <25 } \\
\text { - FM6 GOX SNR decreases } \\
\text { even when the temperature } \\
\text { is not over its red high limit }\end{array}$ & $\begin{array}{l}\text { - Turn on GOX at definite time for } \\
\text { one orbit at low beta angle, GOX } \\
\text { On } 4 \mathrm{~h} \text { Off } 4 \mathrm{~h} \text { cycle to maintain } \\
\text { GOX RO in a stable lower level } \\
\text { around } 120 \text { profiles } \\
\text { - After two months of minus beta } \\
\text { angle (2009-086), S/C flipped } \\
\text { back while RF3 is setting OCC } \\
\text { antenna, GOX operates in full } \\
\text { duty cycle, GOX RO increased to } \\
\text { around } 300 \text { profiles }\end{array}$ & $\begin{array}{l}\text { - GOX performance is de- } \\
\text { creasing even though the } \\
\text { temperature is still within } \\
\text { the limits } \\
\text { - GOX component detail } \\
\text { thermal analysis, thermal } \\
\text { verification, and thermal } \\
\text { model correlation about } \\
\text { thermal verification should } \\
\text { be performed to make sure } \\
\text { its component thermal } \\
\text { design is OK }\end{array}$ \\
\hline
\end{tabular}

Note: SADA = Solar Array Drive Assembly. 
Table 8. Spacecraft system lessons learned.

\begin{tabular}{|c|c|c|c|}
\hline Items & Implementation & Observation/Major finding & Lessons learned \\
\hline SSR/MIU & & & \\
\hline $\begin{array}{l}\text { GOX Data } \\
\text { Dropouts }\end{array}$ & $\begin{array}{l}\text { - GOX data dropout avoidance design was } \\
\text { not implemented in the design require- } \\
\text { ments and the data dropout scenario was } \\
\text { not detected at the subsystem or system } \\
\text { level }\end{array}$ & $\begin{array}{l}\text { - GOX data dropouts occurred in almost } \\
\text { every dump at the payload checkout in } \\
\text { the early orbit phase } \\
\text { - Separate VC1 and VC2 data dumps and } \\
\text { perform double dumps to mitigate the } \\
\text { data dropouts }\end{array}$ & $\begin{array}{l}\text { - Reliable design of interface and proto- } \\
\text { col for data transfer should be specified } \\
\text { in the hardware/software design require- } \\
\text { ments } \\
\text { - No data dropouts must be proven and/or } \\
\text { tested before flight }\end{array}$ \\
\hline
\end{tabular}

Spacecraft

Design

Philosophy
- FS-3/C is a proof-of- concept experimental mission. High reliability and robust design was not implemented in this program

- FS-3/C uses single string design strategy
- System Level FDC (Fault Detection \& Correction) strategy is applied to allow faults to happen and the $\mathrm{S} / \mathrm{C}$ to recover from them

- Temporary loss of the payload performance is much more significant for 1 out of $6 \mathrm{~S} / \mathrm{C}$ in the FS-3/C constellation than 1 out of $30+$ spacecraft in a fleet like in ORBCOMM when using multiple spacecraft as the constellation design redundancy philosophy

\section{Spacecraft}

Downtime
- Due to the single string design, the spacecraft may often encounter anomalies that cause spacecraft downtime for various durations depending on the types of the anomalies

- S/C downtime events will force payload power off and will reduce the GOX RO science data volume
- Top three causes of the spacecraft anomalies are attitude excursions, stabilized mode after thrust burn, and processor reboot/reset. These causes have contributed to appx. three quarters of all payload power off events

- Some anomalies can be resolved by the ground operation solution to maximize GOX RO science data volume
- Apply robust design and high reliability design philosophy for the operational mission

- Continue to apply system-level FDC and implement the necessary redundancy design in the spacecraft as well as in the constellation for the sufficient operational service availability in the followon mission

\begin{tabular}{ll}
\hline $\begin{array}{l}\text { Computers } \\
\text { Resets/ } \\
\text { Reboots }\end{array}$ & $-\begin{array}{l}\text { FS-3/C uses single string design strategy } \\
\text { where none of the computers have a re- } \\
\text { dundant design }\end{array}$ \\
& $-\begin{array}{l}\text { The occurrence frequency of the Single } \\
\text { Event Upset (SEU) is not defined clearly } \\
\text { in the requirements documents } \\
-\end{array}$ \\
& The SEU anomalies made the spacecraft \\
& lose valuable telemetry and payload data
\end{tabular}

- 262 out of 304 events are computer resets/reboots as-of-4-1-2010

- Most of the time and geo-locations the spacecraft anomalies that occurred are correlated to the space radiation environment

- Root cause is due to the occurrence of Single event upset (SEU) in the South Atlantic Anomaly (SAA) and the polar regions

- The spacecraft will be recovered automatically following system level Failure Detection and Correction (FDC) strategies
- Re-design ADCS thrust mode to be able to perform orbit maneuver correctly and improve ADCS performance

- Use high reliable Processor/FPGA

- Form a separate ADCS IV\&V team to evaluate ADCS design, simulation, and test results to prevent errors that cause $\mathrm{S} / \mathrm{C}$ downtime
- Spacecraft design with nonvolatile memory is recommended to secure lost critical spacecraft telemetry and payload data

- Higher level red-tolerant or radiationhardening design should be considered in the future

- Similar FDC function should be also implemented

\begin{tabular}{ll}
\hline ADCS & \\
Performance & $-\begin{array}{l}\text { The ADCS was equipped with only a } \\
\text { coarse attitude sensor and without a rate } \\
\text { sensor } \\
-\end{array}$ \\
& $\begin{array}{l}\text { The sun sensor processing algorithm } \\
\text { generated incorrect sun vector data pe- } \\
\text { riodically }\end{array}$
\end{tabular}

\section{ADCS} riodically
- The attitude performance is not stable resulting in impacts to the GOX payload operation

- Singularity occurred at each orbit to the FS-3 magnetic -based controller/estimator

- The parameters of the attitude reference system have been tuned to gain better attitude performance
- Better performance of attitude sensor, for example star tracker, may be used to improve the ADCS dramatically

- Rate sensor, even the coarse rate sensor, will improve the Thrust Mode performance and therefore decrease the duration of the constellation deployment

- The three-wheel (or four - wheel) zeromomentum- bias linear control system should be considered in future missions

Note: SSR/MIU = Solid State Recorder/Mission Interface Unit, VC1 = Virtual Channel No. 1, VC2 = Virtual Channel No. 2, FDC= Failure Detection Correction, FPGA=Field Programmable gate Array, IV\&V = Independent Verification and Validation, $C \& D H=$ Command and Data Handling , FS-3 = FORMOSAT-3. 

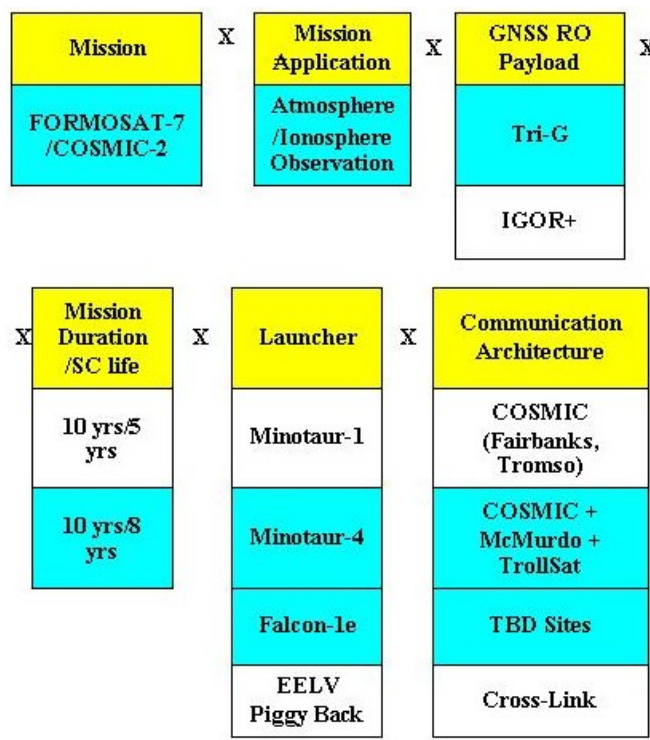
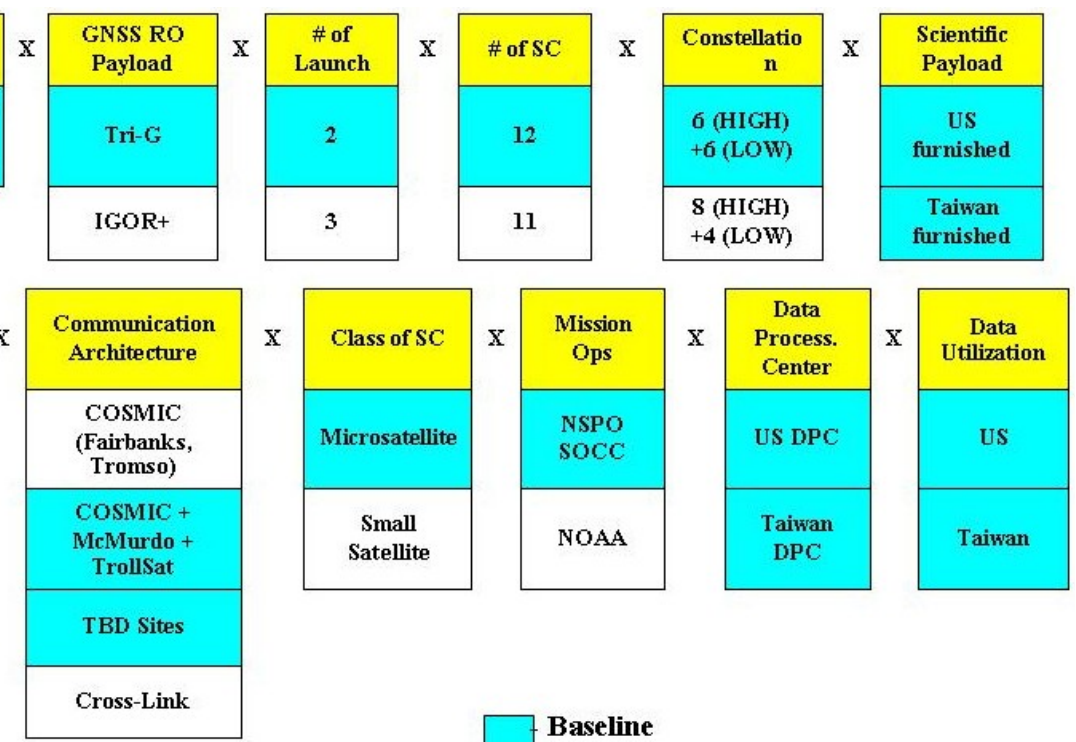

Baseline

Fig. 5. FS-7/C-2 Mission Trades.

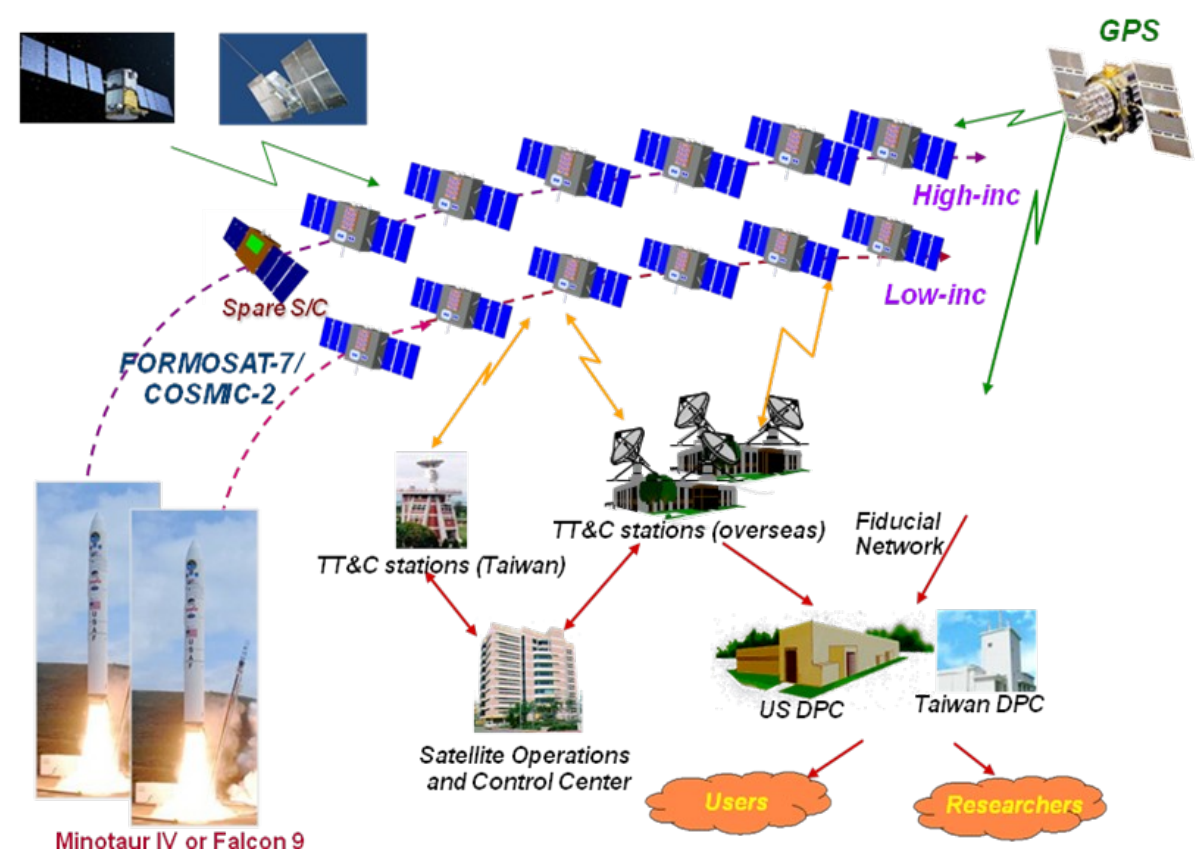

Fig. 6. Proposed FS-7/C-2 Mission Architecture.

stations will be required. Conceptually there would be 3-4 ground stations in the Americas and an additional set of 3-4 in Asia-Indonesia. Figure 7 shows an optimized set of potential ground station locations to meet the low-inclination orbit plane threshold latency, as well as providing coverage for some of the high-inclination orbit plane passes. The yellow circles are the 10 degree elevation coverage circle of the potential ground stations, when LEO satellite passes within this yellow circle, then satellite could be acquired by the ground station located in the circle center. In the figure, the upper red line is 24 degree northern latitude, and the lower red line is the 24 degree southern latitude. These two lines are the upper and lower bound of the low-inclination satellite trajectories of the launch \#1. Trades are currently being performed to look at existing ground station options versus deploying FS7/C-2 unique sites that are optimized to meet mission needs.

To meet the objective latency, two options are currently being studied - a more extensive network of ground stations 
Table 9. Spacecraft Bus Design for Follow-on System vs. FS-3/C.

\begin{tabular}{|c|c|c|c|}
\hline Function & $\begin{array}{l}\text { FS-7/C-2 Design } \\
\text { Improvement }\end{array}$ & FS-3/C Design & Benefit \\
\hline Weight & $\sim 150 \mathrm{~kg}(\mathrm{TBR})$ & 61 kg (w/ Propellant) & $\begin{array}{l}\text { Stacked or Single Launch } \\
\text { Piggy-Back Launch }\end{array}$ \\
\hline $\begin{array}{l}\text { Attitude } \\
\text { Control } \\
\text { Performance }\end{array}$ & $\begin{array}{l}\text { 3-axis linear control } \\
\text { Roll/Yaw: }+/-1 \text { deg. }(3 \sigma) \\
\text { Pitch: }+/-1 \text { deg. }(3 \sigma) \\
\text { 3-Axis Gyro, 3-axis MAG, CSSAs, } \\
\text { RWA x 3, Torque x 3, Star Tracker x } \\
1\end{array}$ & $\begin{array}{l}\text { 3-axis nonlinear control } \\
\text { Roll/Yaw: }+/-5 \text { deg. }(1 \sigma) \\
\text { Pitch: }+/-2 \text { deg. }(1 \sigma) \\
\text { Earth Sensor x } 2 \text {, CSSA x } 8 \text {, RWA x } 1 \text {, } \\
\text { Torque x } 3 \text {, } \\
\text { GPS Bus Receiver PL x } 1\end{array}$ & $\begin{array}{l}\text { Improved PL Performance } \\
\text { Better Attitude Performance } \\
\text { Simplified Operation } \\
\text { Simplified Orbit Transfer }\end{array}$ \\
\hline $\begin{array}{l}\text { Science Data } \\
\text { Storage }\end{array}$ & 250 MBytes & 128 MByte (32M for GOX) & Simplified Operations \\
\hline $\begin{array}{l}\text { Avionics } \\
\text { Architecture }\end{array}$ & $\begin{array}{l}\text { Centralized Architecture } \\
\text { Radiation - Hardness }\end{array}$ & $\begin{array}{l}\text { Distributed Architecture } \\
\text { (Multiple Avionics Boxes) }\end{array}$ & $\begin{array}{l}\text { Simplified Integration } \\
\text { Harnessing \& Reduced Mass }\end{array}$ \\
\hline $\begin{array}{l}\text { Electrical } \\
\text { Power }\end{array}$ & $\begin{array}{l}\text { Lithium Ion Battery } \\
\text { Voltage Based Algorithm }\end{array}$ & $\begin{array}{l}\text { Ni-H2 Battery } \\
\text { dM/dC Charging Algorithm }\end{array}$ & $\begin{array}{l}\text { Reduced Mass \& Volume } \\
\text { Simplified Operations }\end{array}$ \\
\hline Structure & Aluminum $(\mathrm{Al})$ & Metal Matrix & Reduced Cost \\
\hline $\begin{array}{l}\text { Payload } \\
\text { Interface }\end{array}$ & $\begin{array}{l}\text { - Mission PL: TriG Rcvr } \\
\text { - Science PL VIDI \& Radio } \\
\text { Frequency (RF) Beacon on } \\
\text { low inclination satellites } \\
\text { - Science PL on high inclination } \\
\text { satellites TBD }\end{array}$ & $\begin{array}{l}\text { - Primary PL: GOX } \\
\text { - Secondary PL: TIP, TBB }\end{array}$ & $\begin{array}{l}\text { - Modular Design } \\
\text { Reduced Cost }\end{array}$ \\
\hline
\end{tabular}

Note: $\mathrm{TBR}=$ To Be Reviewed, TBD = To Be Determined, MAG = Magnetometer, CSSAs = Coarse Sun Sensor Assemblies, RWA= Reaction Wheel Assembly, VIDI = Velocity, Ion Density and Irregularities.

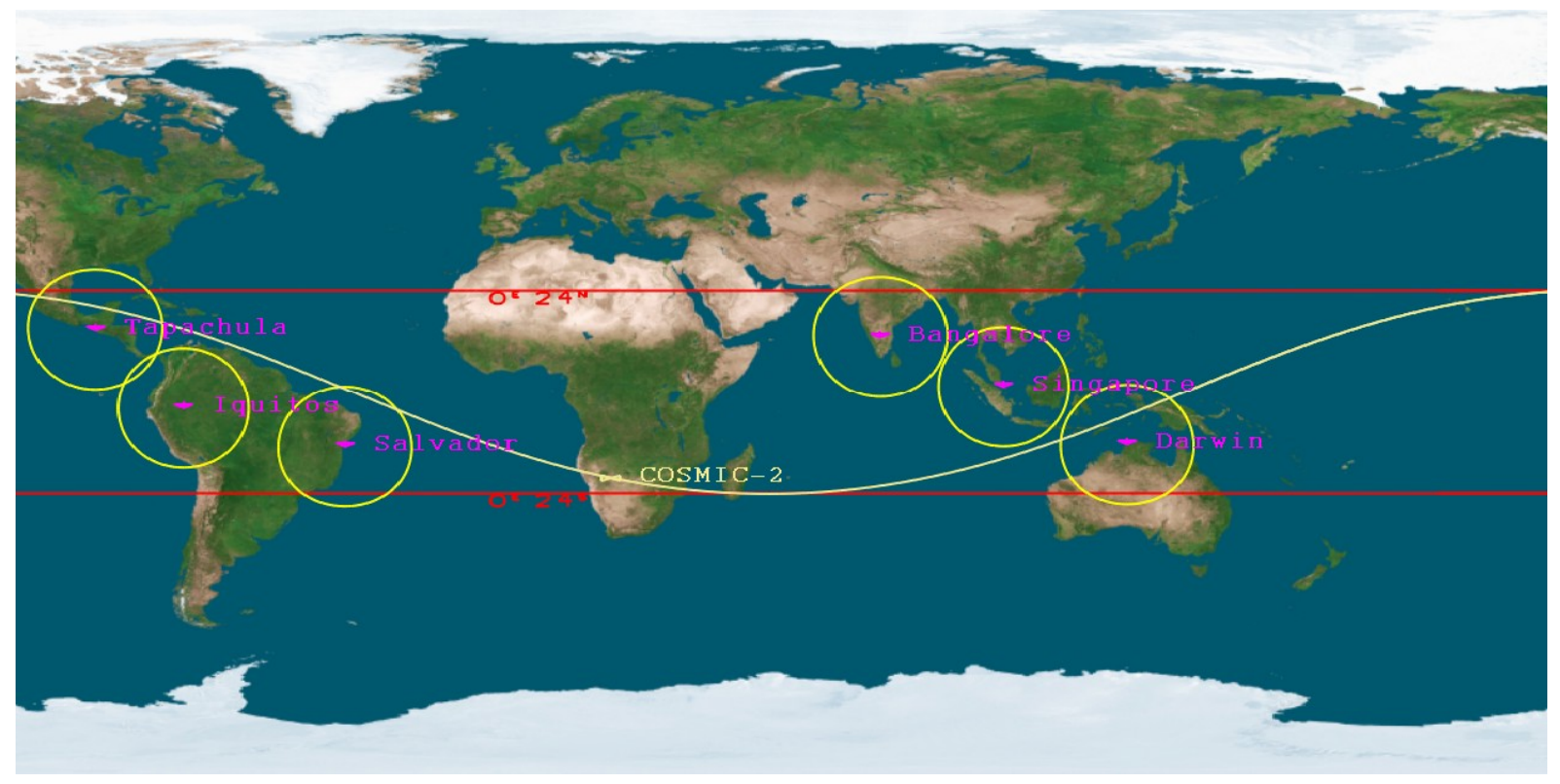

Fig. 7. Potential FS-7/C-2 Equatorial Ground Station Locations. 
and crosslink via the National Aeronautic and Space Administration's (NASA) Tracking and Data Relay Satellite System (TDRSS). Both are currently being considered as part of this trade and implementation will depend largely on the total cost to deploy and operate the option. A ground station solution will be difficult to deploy but if stations could be leveraged from existing sites and/or future programs it may be more feasible and very cost effective to operate. On the other hand, TDRSS would be relatively easy to deploy but be potentially expensive for long term service.

Another item in the ground system trade is alternate data transfer options from the ground stations to the data processing centers to better meet latency needs of multiple users. SFTP via the world wide web to multiple users, including potential secondary payload data centers, may not provide adequate latency. Dedicated communication lines may be required to meet the more stringent latency requirements.

\subsection{Data processing trades and improvements}

Data processing architecture for FS-7/C-2 will remain relatively the same as FS-3/C but will require reliable and low latency input data from FS-7/C-2 GNSS-RO payloads and GNSS ground network, updates to data processing software including GNSS (GPS, Galileo, and Glonass) capability, and more computational power to support the improved and additional number of RO instruments. To make data processing more robust for an operational environment, a data processing system (DPS) will be installed at the Environmental Satellite Processing Center (ESPC) in NOAA's Satellite Operations Facility (NSOF) in Suitland, Maryland. ESPC will be the prime data processing center in the United States for FS-7/C-2, providing GNSS-RO data products to the operational weather community. NOAA will provide longterm archive of FS-7/C-2 data in their Comprehensive Large Array-Data Stewardship System (CLASS).

\section{Conclusions}

The FS-3/C satellites have performed successfully for over $4 \mathrm{yr}$. It is not a perfect constellation for an operational system, but it has achieved more than satisfactory results for an experimental system operating in a semi-operational manner. The FS-3/C satellites are degrading as anticipated; however, NSPO assesses these satellites will continue to operate in a reduced capacity for the next few years. The success of the FS-3/C mission has initiated a new era for near real-time operational use of GNSS-RO soundings. NSPO is committed to continuing the FS-3/C satellite constellation operation to collect RO data to minimize the data gap duration between the end of FS-3/C and the beginning of FS-7/C-2. NSPO and NOAA have already begun the FS-7/C-2 joint mission implementation.

\section{Appendix A}

\section{Acronyms and abbreviations}

\begin{tabular}{|c|c|}
\hline $\mathrm{ACE}$ & Attitude Control Electronics \\
\hline ADCS & $\begin{array}{l}\text { Attitude Determination and Control } \\
\text { Subsystem }\end{array}$ \\
\hline AFWA & Air Force Weather Agency \\
\hline Ant\# & Antenna No. \# \\
\hline ATT & Attitude \\
\hline BCR & Battery Charge Regulator \\
\hline C\&DH & Command and Data Handling \\
\hline CDAAC & $\begin{array}{l}\text { COSMIC Data Analysis and Archive } \\
\text { Center }\end{array}$ \\
\hline CHAMP & Challenging Minisatellite Payload \\
\hline COSMIC & $\begin{array}{l}\text { Constellation Observing Systems for } \\
\text { Meteorology, Ionosphere, and Climate }\end{array}$ \\
\hline Canada Met & Canadian Meteorological Centre \\
\hline CLASS & $\begin{array}{l}\text { Comprehensive Large Array-Data } \\
\text { Stewardship System }\end{array}$ \\
\hline CSSA & Coarse Sun Sensor Assembly \\
\hline CSSA\# & Coarse Sun Sensor Assembly no. \# \\
\hline CWB & Central Weather Bureau \\
\hline DC & Direct Current \\
\hline $\mathrm{dMdC}$ & $\begin{array}{l}\text { Derivative of Battery Molecular } \\
\text { to Charge }\end{array}$ \\
\hline DPC & Data Processing Center \\
\hline DPS & Data Processing System \\
\hline ECMWF & $\begin{array}{l}\text { European Centre for Medium-range } \\
\text { Weather Forecast }\end{array}$ \\
\hline EPS & Electrical Power Subsystem \\
\hline ESPC & $\begin{array}{l}\text { Environmental Satellite Processing } \\
\text { Center }\end{array}$ \\
\hline FB & Firmware Build \\
\hline FC & Flight Computer \\
\hline FCDAS & $\begin{array}{l}\text { Fairbanks Command and Data } \\
\text { Acquisition Station }\end{array}$ \\
\hline FDC & Failure Detection Correction \\
\hline FM & Flight Model \\
\hline FM\# & Flight Model no. \# \\
\hline FPGA & Field Programmable Gate Array \\
\hline FS-3 & FORMOSAT-3 \\
\hline FS-7/C-2 & $\begin{array}{l}\text { FORMOSA SATellite mission no.7/ } \\
\text { Constellation Observing Systems for } \\
\text { Meteorology, Ionosphere, and Climate } \\
\text { mission no. } 2\end{array}$ \\
\hline FSW & Flight Software \\
\hline GLONASS & Global Navigation Satellite System \\
\hline GNSS & Global Navigation Satellite Systems \\
\hline GPS & Global Positioning System \\
\hline GPS/MET & GPS/Meteorology \\
\hline GOX GPS & Occultation Receiver \\
\hline GPSR GPS & Receiver \\
\hline GRACE & $\begin{array}{l}\text { Gravity Recovery and Climate } \\
\text { Experiment }\end{array}$ \\
\hline
\end{tabular}




\begin{tabular}{|c|c|}
\hline GTS & Global Telecommunications System \\
\hline I\&T & Integration and Test \\
\hline IV\&V & Independent Verification and Validation \\
\hline JMA & Japan Meteorological Agency \\
\hline JPL & Jet Propulsion Laboratory \\
\hline JSCDA & $\begin{array}{l}\text { Joint Center for Satellite Data } \\
\text { Assimilation }\end{array}$ \\
\hline KSAT & $\begin{array}{l}\text { Kongsberg Satellite Services Ground } \\
\text { Station }\end{array}$ \\
\hline LEO & Low-Earth-Orbit \\
\hline LOS & Loss of Signal \\
\hline LTS & Local Tracking Station \\
\hline MAG & Magnetometer \\
\hline Météo-France & French National Meteorological Service \\
\hline MIU & Mission Interface Unit \\
\hline NARL & National Applied Research Laboratories \\
\hline NASA & $\begin{array}{l}\text { National Aeronautics and Space } \\
\text { Administration }\end{array}$ \\
\hline CAR & $\begin{array}{l}\text { National Center for Atmospheric } \\
\text { Research }\end{array}$ \\
\hline NCEP & $\begin{array}{l}\text { National Centers for Environmental } \\
\text { Prediction }\end{array}$ \\
\hline NESDIS & $\begin{array}{l}\text { National Environmental Satellite, Data, } \\
\text { and Information Service }\end{array}$ \\
\hline NOAA & $\begin{array}{l}\text { National Oceanic and Atmospheric } \\
\text { Administration }\end{array}$ \\
\hline NSC & National Science Council \\
\hline NSF & National Science Foundation \\
\hline NSOF & NOAA's Satellite Operations Facility \\
\hline NSPO & National Space Organization \\
\hline NWP & Numerical Weather Prediction \\
\hline OCC\# & Occultation No. \# \\
\hline OSC & Orbital Sciences Corporation \\
\hline PCM & Power Control Module \\
\hline PL & Payload \\
\hline POD & Precision Orbit Determination \\
\hline POD\# & Precision Orbit Determination No. \# \\
\hline $\mathrm{RF}$ & Radio Frequency \\
\hline RF\# & Radio Frequency No. \# \\
\hline RFI & Radio Frequency Interference \\
\hline RO & Radio Occultation \\
\hline RTS & Remote Tracking Station \\
\hline RWA & Reaction Wheel Assembly \\
\hline SAA & South Atlantic Anomaly \\
\hline SAC-C & Satellite de Aplicaciones Cientificas-C \\
\hline SADA & Solar Array Drive Assembly \\
\hline $\mathrm{S} / \mathrm{C}$ & Spacecraft \\
\hline SFTP & Secure File Transfer Protocol \\
\hline SNR & Signal-to-Noise Ratio \\
\hline SOC & State-of-Charge \\
\hline SOCC & Satellite Operations Control Center \\
\hline $\mathrm{SOH}$ & State-of-Health \\
\hline SSR & Solid State Recorder \\
\hline TACC & Taiwan Analysis Center for COSMIC \\
\hline TBB & Tri-Band Beacon \\
\hline & To Be Reviewed \\
\hline
\end{tabular}

TDRSS Tracking and Data Relay Satellite System

TEC Total Electron Content

TIP Tiny Ionospheric Photometer

UCAR University Corporation for Atmospheric

Research

UKMO United Kingdom Meteorological Office

USA United States of America

USAF United States Air Force

USN United Service Network

VC\# Virtual Channel No. \#

VIDI Velocity, Ion Density and Irregularities

WCDAS Wallops Command and Data

Acquisition Station

ZTD Zenith Tropospheric Delay

\section{Supplementary material related to this \\ article is available online at: \\ http://www.atmos-meas-tech.net/4/1115/2011/ amt-4-1115-2011-supplement.pdf.}

\begin{abstract}
Acknowledgements. The authors would like to thank the spacecraft team for providing four-year statistical trend data in various subsystems. They would like to thank the contributions of the FS-3/C Program, the FS-7/C-2 Program, mission operations, flight operations, ground operations, constellation deployment, and anomaly resolution teams; the Taiwan science teams; and the cooperation partners with the NSC, NARL, CWB, NSF, UCAR, NCAR, JPL/NASA, NRL, USAF, OSC, and NOAA.
\end{abstract}

Edited by: A. K. Steiner

\section{References}

Anthes, R. A., Rocken, C., and Kuo, Y. H.: Application of COSMIC to Meteorology and Climate, Terr., Atmos. Ocean. Sci., 11(1), 115-156, 2000.

Anthes, R. A., Bernhardt, P. A., Chen, Y., Cucurull, L., Dymond, K. F., Ector, D., Healy, S. B., Ho, S.-P., Hunt, D. C., Kuo, Y.-H., Liu, H., Manning, K., McCormick, C., Meehan, T. K., Randel, W. J., Rocken, C., Schreiner, W. S., Sokolovskiy, S. V., Syndergaard, S., Thompson, D. C., Trenberth, K. E., Wee, T. K., Yen, N. L., and Zeng, Z.: The COSMIC / FORMOSAT-3 Mission: Early Results, B. Am. Meteorol. Soc., 89(3), 313-333, doi:10.1175/BAMS-89-3-313, 2008.

Chu, C.-H., Yen, N., Hsiao, C.-C., Fong, C.-J., Yang, S.-K., Liu, T.Y., Lin, Y.-C., and Miau, J.-J.: Earth observations with orbiting thermometers - prospective FORMOSAT-3/COSMIC follow-on mission, Proceedings of Small Satellite Conference 2008, Logan, Utah., USA, Logan, 2008.

Fong, C.-J., Shiau, A., Lin, T., Kuo, T.-C., Chu, C.-H., Yang, S.K., Yen, N., Chen, S. S., Huang, C.-Y., Kuo, Y.-H., Liou, Y.A., and Chi, S.: Constellation deployment for FORMOSAT3/COSMIC mission, IEEE T. Geosci. Remote, 46(11), 3367 3379, doi:10.1109/TGRS.2008.2005202, 2008a.

Fong, C.-J., Yang, S.-K., Chu, C.-H., Huang, C.-Y., Yeh, J.J., Lin, C.-T., Kuo, T.-C., Liu, T.-Y., Yen, N., Chen, S. S., 
Kuo, Y.-H., Liou, Y.-A., and Chi, S.: FORMOSAT-3 / COSMIC constellation spacecraft system performance: After One Year in Orbit, IEEE T. Geosci. Remote, 46(11), 3380-3394, doi:10.1109/TGRS.2008.2005203, 2008b.

Fong, C.-J., Huang, C.-Y., Chu, V., Yen, N., Kuo, Y.-H., Liou, Y.A., and Chi, S.: Mission results from FORMOSAT-3/COSMIC constellation system, AIAA J. Spacecraft Rockets, 45(6), 12931302, doi:10.2514/1.34427, 2008c.

Fong, C.-J., Yen, N. L., Chu, C.-H., Yang, S.-K., Shiau, W.-T., Huang, C.-Y., Chi, S., Chen, S.-S., Liou, Y.-A., and Kuo, Y.-H.: FORMOSAT-3/COSMIC spacecraft constellation system, mission results, and prospect for follow-on mission, Terr. Atmos. Ocean. Sci., 20(1), 1-19, doi:10.3319/TAO.2008.01.03.01(F3C), 2009a.

Fong, C.-J., Yen, N. L., Chu, C.-H., Hsiao, C.-C., Liou, Y.A., and Chi, S.: Space-based Global Weather Monitoring System - FORMOSAT-3/COSMIC Constellation and its FollowOn Mission, AIAA J. Spacecraft Rockets, 46(4), 883-891, doi:10.2514/1.41203, 2009b.

Fong, C.-J., Whiteley, D., Yang E., Cook, K., Chu, V., Schreiner, B., Ector, D., Wilczynski, P., and Yen, N. Y.: Space \& Ground Segment Performance of the FORMOSAT-3 / COSMIC Mission: Four Years in Orbit, Joint OPAC-4 \& GRAS-SAF Climate \& IROW-1 Workshop, Graz, Austria, 2010.

Hajj, G. A., Lee, L. C., Pi, X., Romans, L. J., Schreiner, W. S., Straus, P. R., and Wang, C.: COSMIC GPS ionospheric sensing and space weather, Terr. Atmos. Ocean. Sci., 11(1), 235-272, 2000.

Kursinski, E. R. „Hajj, G. A., Bertiger, W. I., Leroy, S. S., Meehan, T. K., Romans, L. J., Schofield, J. T., McCleese, D. J., Melbourne, W. G., Thornton, C. L., Yunck, T. P., Eyre, J. R., and Nagatani, R. N.: Initial results of radio occultation observations of Earth's atmosphere using the Global Positioning System, Science, 271(5252), 1107-1110, 1996.

Kuo, Y.-H., Sokolovskiy, S., Anthes, R., and Vandenberghe, V.: Assimilation of GPS radio occultation data for numerical weather prediction, Terr. Atmos. Ocean. Sci., 11(1), 157-186, 2000.

Kuo, Y.-H., Wee, T.-K., Sokolovskiy, S., Rocken, C., Schreiner, W., Hunt, D., and Anthes, R. A.: Inversion and Error Estimation of GPS Radio Occultation Data, J. Meteorol. Soc. Jpn, 82(1B), 507-531, doi:10.2151/jmsj.2004.507, 2004.

Kuo, Y.-H., Liu, H., Ma, Z., and Guo, Y.-R.: The Impact of FORMOSAT-3/COSMIC GPS Radio Occultation, Proceedings of 4th Asian Space Conference and 2008 FORMOSAT-3 / COSMIC International Workshop, Taipei, Taiwan, NSPO, Hsinchu, Taiwan, 2008.
Liou, Y.-A., Pavelyev, A. G., Liu, S. F., Pavelyev, A. A., Yen, N., Huang, C. Y., and Fong, C.-J.: FORMOSAT-3 GPS radio occultation mission: preliminary results, IEEE T. Geosci. Remote, 45(10), 3813-3824, doi:10.1109/TGRS.2007.903365, 2007.

Luntama, J.-P., Kirchengast, G., Borsche, M., Foelsche, U., Steiner, A., Healy, S., von Engeln, A., O'Clerigh, E., and Marquardt, C.: Prospects of the EPS GRAS Mission For Operational Atmospheric Applications, B. Am. Meteorol. Soc., 89(12), 18631875, doi:10.1175/2008BAMS2399.1, 2008.

Melbourne, W. G.: Radio Occultation Using Earth Satellites: A Wave Theory Treatment, John Wiley \& Sons, Inc., ISBN 0-47171222-1, 2005.

Perona, G., Notarpietro, R., Gabella, M.: GPS radio occultation on-board the OCEANSAT-2 mission: An Indian (ISRO) - Italian (ASI) collaboration, Indian J. Radio Space, 36(5), 386-393, 2007.

Rius, A., Ruffini, G., and Romeo, A.: Analysis of ionospheric electron-density distribution from GPS/MET occultations, IEEE T. Geosci. Remote, 36(2), 383-394, 1998.

Schreiner, W. S., Sokolovskiy, S. V., Rocken, C., and Hunt, D. C.: Analysis and Validation of GPS/MET Radio Occultation Data in the Ionosphere, Radio Sci., 34(4), 949-966, doi:10.1029/1999RS900034, 1999.

Schreiner, W. S., Rocken, C., Sokolovskiy, S., and Hunt, D. C.: Quality assessment of COSMIC/FORMOSAT-3 GPS radio occultation data derived from single- and double-difference atmospheric excess phase processing, GPS Solutions, 14(1), 13-22, doi:10.1007/s10291-009-0132-5, 2009.

Ware, R., Rocken, C., Solheim, F., Exner, M., Schreiner, W., Anthes, R., Feng, D., Herman, B., Gorbunov, M., Sokolovskiy, S., Hardy, K., Kuo, Y., Zou, X., Trenberth, K., Meehan, T., Melbourne, W., and Businger, S.: GPS sounding of the atmosphere from low earth orbit: Preliminary results, B. Am. Meteorol. Soc., 77(1), 19-40, 1996.

Yen, N. L. and Fong, C.-J.: FORMOSAT-3 Evaluation Report and Follow-on Mission Plan, NSPO-RPT-0047_0000, National Space Organization (NSPO), Hsinchu, Taiwan, 2009.

Yen, N. L.: FORMOSAT-3/COSMIC Follow-On Mission Plan and Current Progress, Joint OPAC-4 \& GRAS-SAF Climate \& IROW-1 Workshop, Graz, Austria, 2010.

Yunck, T. P., Liu, C. H., and Ware, R.: A History of GPS Sounding, Terr. Atmos. Ocean. Sci., 11(1), 1-20, 2000. 